\title{
Development and validation of stability- indicating UPLC method for the determination of gliclazide and its impurities in pharmaceutical dosage forms
}

\author{
Kunal Bhattacharya ${ }^{1}$ (D) and Jane Mathew ${ }^{2^{*}}$ (D)
}

\begin{abstract}
Background: For the determination of gliclazide and its three potential impurities quantitatively, the development of a stability-indicating, accurate, simple, and fast, Ultra-Performance Liquid Chromatography (UPLC) method was done.

Results: On Acquity CSH 18 column $(50 \mathrm{~mm} \times 2.1 \mathrm{~mm}, 1.7 \mu)$ separation was achieved by the isocratic elution mode using mobile phase $(5 \mathrm{mM}$ ammonium acetate buffer of $\mathrm{pH} 4$ and $10 \%$ ammonium acetate buffer $+90 \%$ acetonitrile, 65/35 v/v). In total, $0.7 \mathrm{~mL}^{-1}$ was the chosen flow rate and UV detection was carried out at $227 \mathrm{~nm}$.

Conclusion: By analyzing forced degradation products of the sample, the stability-indicating characteristic of the developed method was proved where the separation of the products of degradation from analyte peak was seen along with spectral purity of gliclazide. Validation of the developed UPLC method was done as per the guidelines of the International Conference on Harmonization in terms of system suitability, precision, accuracy, specificity, sensitivity, linearity, and robustness.
\end{abstract}

Keywords: Gliclazide, UPLC, Potential impurity, Stability indicating

\section{Background}

For treating the non-insulin-dependent or type 2 diabetes mellitus, gliclazide is being used as oral hypoglycemic agent. It is an insulin secretagogue that helps the pancreas to increase the production of insulin and belongs to the second generation sulfonylureas due to the presence of a sulphonamide group in its structure. Gliclazide binds on the sulfonylurea receptors (SUR-1) specifically which are present on the pancreatic betacells [1]. Chemically, gliclazide is given as $1-(3,3 a, 4,5,6$, 6a-hexahydro-1H-cyclopenta[c]pyrrol-2-yl)-3-(4-

\footnotetext{
* Correspondence: janej@nitte.edu.in

${ }^{2}$ Department of Pharmaceutical Chemistry, NGSM Institute of Pharmaceutical Sciences, Nitte (Deemed to be University), Deralakatte, Mangalore 575018, India

Full list of author information is available at the end of the article
}

methylphenyl)sulfonylurea [2]. Gliclazide is present in the market with the brand name of Diamicron containing 30,60 , or $80 \mathrm{mg}$ of gliclazide for oral administration in the form of tablets [3]. There is a possibility that decrease in the oxidative stress can improve endothelial functions in vascular diseases thereby having a positive effect on the use of glicazide [4]. Due to its antioxidant properties, intensive glycemic control is observed [5]. Reduction in hyperreactivity of platelet [6], reduced risk of hyperglycemia and cardiovascular safety is also associated with the use of this drug [7].

For the determination of gliclazide and its potential impurities in pharmaceutical dosage forms, analytical method is required to control and monitor the impurities present in the drug-related substances. Several techniques of analysis are hybrid where liquid chromatography (LC) [8], gas chromatography (GC) 
[9], and capillary electrophoresis (CE) [10] are combined to mass spectrometry and are majorly used during reversed-phase liquid chromatography involving a non-polar stationary phase. On doing a literature survey extensively, it was revealed that for the analysis of gliclazide, several high-performance liquid chromatographies (HPLC) were found but to the best of our knowledge, no reported stability-indicating ultra-performance liquid chromatography method for estimating gliclazide is available. Also, there was no such effective analytical method reported which was effective in saving time and money. As analytical studies were done using GC/MSD or LC-MS are highly expensive and fragile in comparison to ultraperformance liquid chromatography (UPLC) and our main focus was on developing an analytical method that is rapid, accurate, reproducible, and costeffective, UPLC method was chosen for the developing stability-indicating method for determining gliclazide. The developed method was validated as per the Q2 (R1) guidelines of the International Conference on Harmonization (ICH) and USP <1225> compendia procedures [11, 12].

\section{Methods}

\section{Materials and reagents}

Gliclazide sample and its three impurities, namely, Imp A, Imp C, and Imp F as shown in Fig. 1 were received from Mylan Laboratories, Hyderabad, India. Trifluoro acetic acid of HPLC grade was procured from J.T.Baker, India. Acetonitrile of HPLC grade and hydrochloric acid of AR grade were procured from Rankem, India. Sodium hydroxide of Emplura grade, formic acid of Emparta grade, hydrogen peroxide $(30 \% \mathrm{v} / \mathrm{v})$ of AR grade, and ammonium acetate of Emparta grade were procured from Merck, India. De-ionized water was procured from Millipore, a Milli-Q purification system installed in Mylan Laboratories.

\section{Instrumentation and operating conditions}

Autosampler and quaternary gradient pump equipped Waters' Acquity UPLC system with photodiode array detector was used in the development of the stabilityindicating method and its validation. Processing of the output signals was performed with the help of Empower software version 2. During the development of the method the UPLC columns used were Acquity $\mathrm{CSH}-\mathrm{C} 18$ column $(50 \mathrm{~mm} \times 2.1 \mathrm{~mm} \times 1.7 \mu)$, Acquity BEH-C18 column $(50 \mathrm{~mm} \times 2.1 \mathrm{~mm} \times 1.7 \mu)$, Phenomenex Kinetex-C18 column $(50 \mathrm{~mm} \times 2.1 \mathrm{~mm} \times 1.7 \mu)$, and Acquity BEH-C18 column $(150 \mathrm{~mm} \times 2.1 \mathrm{~mm} \times 1.7 \mu)$.

Acquity CSH-C18 column $(50 \mathrm{~mm} \times 2.1 \mathrm{~mm} \times 1.7 \mu)$ thermostated at $45{ }^{\circ} \mathrm{C}$ was finally used for separation. The mobile phase was made by mixing $5 \mathrm{mM}$ ammonium acetate buffer of $\mathrm{pH} 4$ and $10 \%$ ammonium acetate buffer $+90 \%$ acetonitrile in the ratio of $65: 35$. The flow

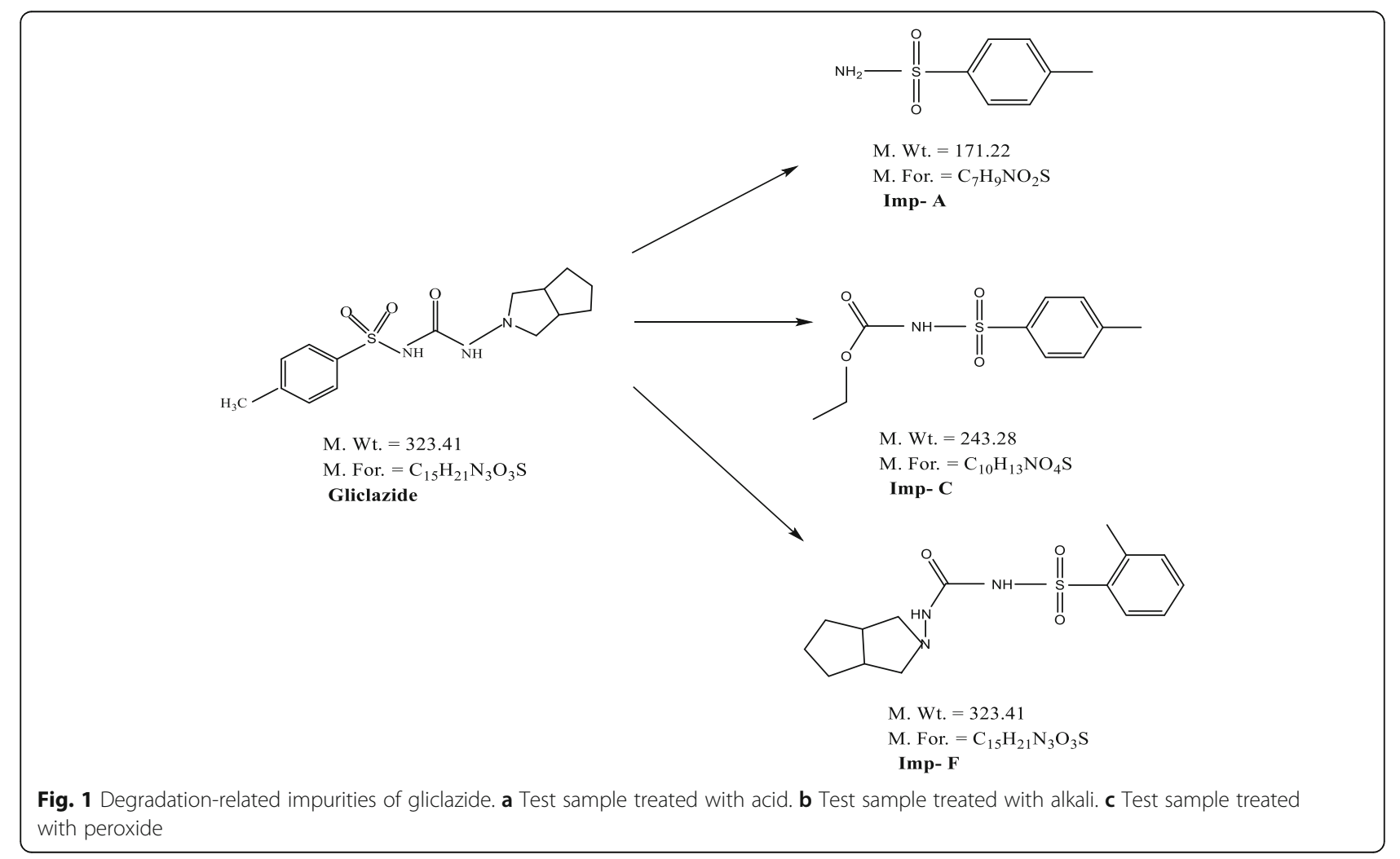


Table 1 Forced degradation study results

\begin{tabular}{|c|c|c|c|c|}
\hline Stress conditions & $\%$ Degradation & Purity angle & Purity threshold & Purity flag \\
\hline Unstressed condition & 0 & 0.068 & 0.317 & No \\
\hline Treated with $1 \mathrm{~N}(5 \mathrm{~mL}) \mathrm{HCL}$ solution for $45 \mathrm{~min}$ on benchtop & 5.5 & 0.088 & 0.416 & No \\
\hline Treated with $1 \mathrm{~N}(5 \mathrm{~mL}) \mathrm{NaOH}$ solution for $2 \mathrm{~h}$ at $95^{\circ} \mathrm{C}$ & 5.8 & 0.056 & 0.357 & No \\
\hline Treated with $3 \%(5 \mathrm{~mL}) \mathrm{H}_{2} \mathrm{O}_{2}$ solution for $1 \mathrm{~h}$ at benchtop & 13.9 & 0.058 & 0.308 & No \\
\hline Treated with $\mathrm{H}_{2} \mathrm{O}(5 \mathrm{~mL})$ for $2 \mathrm{~h} 90^{\circ} \mathrm{C}$ & 18.4 & 0.297 & 0.314 & No \\
\hline Kept in oven at $105^{\circ} \mathrm{C}$ for and $72 \mathrm{~h}$ & 0.9 & 0.089 & 0.408 & No \\
\hline $\begin{array}{l}\text { Kept in humidity chamber for } 120 \mathrm{~h} \text { at } 75 \% \\
\text { Relative humidity and } 40{ }^{\circ} \mathrm{C}\end{array}$ & 0.1 & 0.102 & 0.421 & No \\
\hline
\end{tabular}

rate was kept at $0.7 \mathrm{~mL}^{-1}$ and injection volume was 2 $\mu \mathrm{L}$. The data were obtained at $227 \mathrm{~nm}$ for $3 \mathrm{~min}$ and further, it was processed using the Empower 2 software. Scanning from 200-400 nm using the photodiode array detector was done for forced degradation study analysis and in terms of peak purity, the peak homogeneity was calculated.

\section{Solution preparations}

Glicazide is insoluble in water but soluble in acetonitrile. To reduce the organic solvent consumption, different ratios of acetonitrile and ammonium buffer of $\mathrm{pH} 7.4$ was tried to study the solubility and finally acetonitrile and $\mathrm{pH} 7.4$ ammonium acetate buffer in the ratio 70:30 was found to be suitable with good solubility, was fixed as diluent 1 for complete extraction of the drug, acetonitrile and ammonium acetate buffer ( $\mathrm{pH}$ 7.4) in ratio of 50:50 was fixed as diluent 2 for chromatographic run. Diluent 1 used in the analysis was made by degassing a mixture of $700 \mathrm{~mL}$ of acetonitrile with $300 \mathrm{~mL}$ of $\mathrm{pH} 7.45 \mathrm{mM}$ ammonium acetate buffer and diluent 2 was prepared by degassing a mixture of 500 volume of acetonitrile with $500 \mathrm{~mL}$ of $\mathrm{pH} 7.45 \mathrm{mM}$ ammonium acetate buffer. A standard solution of $480 \mu \mathrm{g} \mathrm{mL}{ }^{-1}$ concentration of gliclazide was prepared by dissolving $60 \mathrm{mg}$ of drug in $50 \mathrm{~mL}$ of diluent 1 and then $4 \mathrm{~mL}$ of this above solution was diluted using $6 \mathrm{~mL}$ of diluent 2 . The stock solution of each impurity (Imp-A, Imp-C, and Imp-F) were made at a concentration of $72 \mu \mathrm{g}$ $\mathrm{mL}^{-1}$ using diluent 1 . For preparing a standard solution for purpose of quantifying the impurities in accordance with the specified limits (0.15\%) of individual impurity, further dilution of these solutions was carried out using diluent 2 .

Sample solution of drug formulation was prepared by transferring accurately weighed 10 tablets of gliclazide into a dry $500 \mathrm{~mL}$ volumetric flask. Thirty milliliters of acetonitrile was added to the volumetric flask and stirred for $10 \mathrm{~min}$ using a magnetic stirrer after placing a magnetic bead inside the volumetric flask for disintegration of tablets. After the disintegration of tablets, $350 \mathrm{~mL}$ of diluent 1 was added and stirred for $90 \mathrm{~min}$ and the solution was further sonicated for $45 \mathrm{~min}$ with occasional shaking at an interval of 5 min. The magnetic bead was removed using a bead retriever and volume was made till the $500 \mathrm{~mL}$ mark using diluent 1 in the volumetric flask. A portion of the solution taken out of the volumetric flask was centrifuged at an RPM of 5000 for $10 \mathrm{~min}$. From the centrifuged solution, $4 \mathrm{~mL}$ of the solution was pipetted out into a volumetric flask of $10 \mathrm{~mL}$ and volume was made up to the mark using diluent 2 to get a sample concentration of $480 \mu \mathrm{g} \mathrm{mL}{ }^{-1}$.

\section{Analytical procedure}

Gliclazide solution having a concentration of $480 \mu \mathrm{g}$ $\mathrm{mL}^{-1}$ was spiked with Imp-C, Imp-A, and Imp-F at a specified level of 0.15 percent and considered as a standard stock solution. Using $2 \mu \mathrm{L}$ each blank preparation as standard stock solution, under chromatographic conditions, six replicates of standard solution and six replicates of test solutions were injected and chromatograph was obtained. Not less than 2.0 was set as a resolution criterion between gliclazide and its related compound F was set as a parameter of system suitability. During verification of the system precision, not more than 5\% RSD was recorded for injecting six replicate injections of all impurities.

\section{Forced degradation study procedure}

Based on In-lab developed protocol, a study was conducted to show the effective separation of degradants from gliclazide peak in assay method. Separate portions of blank, placebo, and drug product were treated with $1 \mathrm{~N} \mathrm{HCl}(5 \mathrm{~mL})$ solution for $45 \mathrm{~h}$ at benchtop, $1 \mathrm{~N} \mathrm{NaOH}$ (5 mL) solution for $2 \mathrm{~h}$ at $95{ }^{\circ} \mathrm{C}, 3 \% \mathrm{H}_{2} \mathrm{O}_{2}(5 \mathrm{~mL})$ solution for $1 \mathrm{~h}$ at benchtop, treated with $\mathrm{H}_{2} \mathrm{O}(5 \mathrm{~mL})$ solution for $2 \mathrm{~h}$ at $90{ }^{\circ} \mathrm{C}$. After the treatment, the solutions were diluted till the mark to get concentration of $480 \mu \mathrm{g}$ $\mathrm{mL}^{-1}$. Thermal degradation of solid API was done by keeping the sample in a hot air oven at $105^{\circ} \mathrm{C}$ for $72 \mathrm{~h}$. Photolytic degradation of the sample was done by exposing it to a UV source for 7 days and humidity 
a Test sample treated with acid

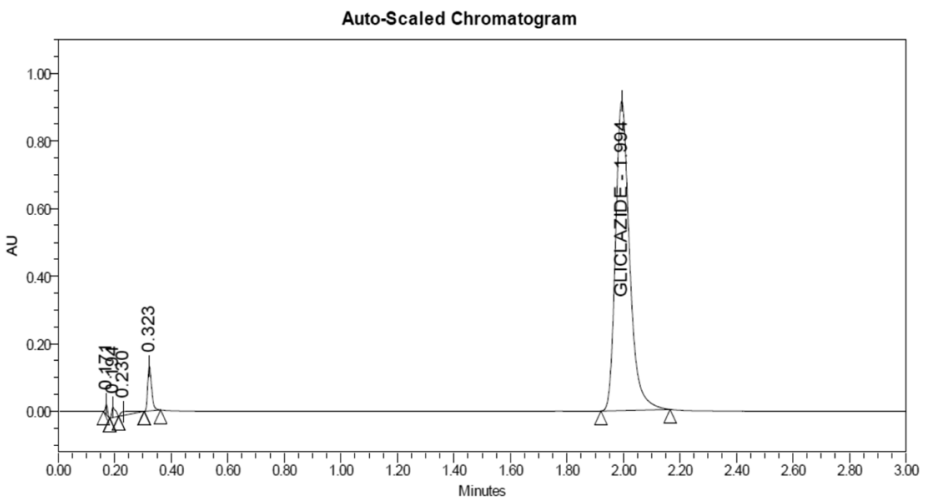

b Test sample treated with alkali

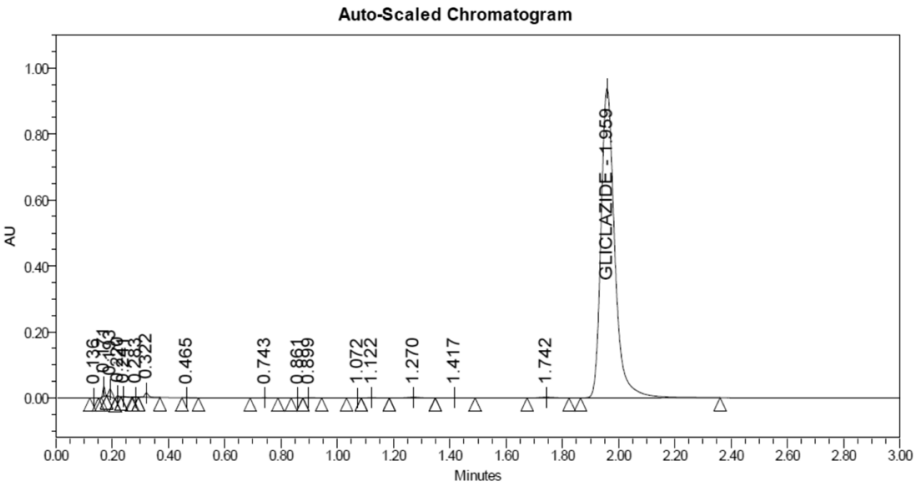

c Test sample treated with peroxide

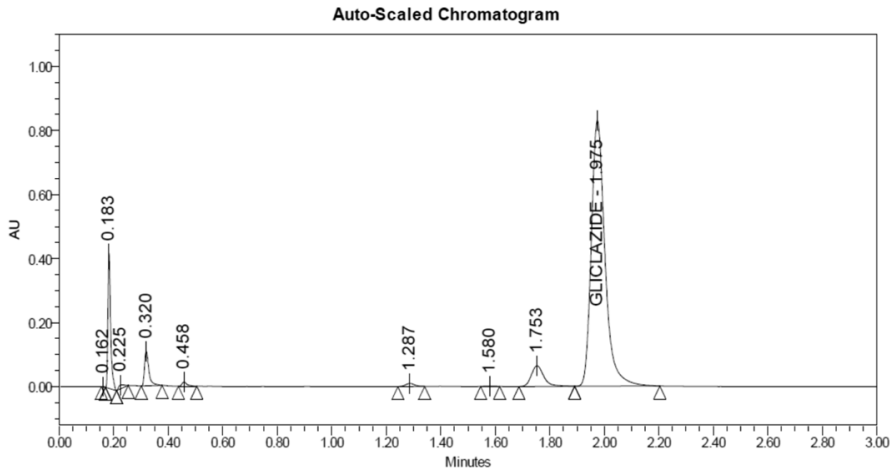

Fig. $\mathbf{2}$ UPLC chromatograms of forced degradation study. a Test sample treated with acid, $\mathbf{b}$ test sample treated with base, and $\mathbf{c}$ test sample treated with peroxide

degradation of the sample was done by keeping the sample chamber having $75 \%$ relative humidity at $40{ }^{\circ} \mathrm{C}$ for $120 \mathrm{~h}$.

Analyses of stressed samples were done as per the test method using a photodiode array detector. Chromatograms obtained were examined for peak purity of peak with the help of Waters Empower 2 software. Standard and sample solutions prepared, using ammonium acetate buffer, were stable during the analysis as gliclazide is insoluble in water and the percentage of buffer used was significantly lower when compared to acetonitrile used as organic solvent. Purity angle was lower than purity threshold without purity flag for gliclazide peak for all forced degradation samples which indicated that in the quantification of the gliclazide in gliclazide tablets, there is no interference from degradants (Table 1).

Calculation of percentage degradation is calculated using the formula: [13] 


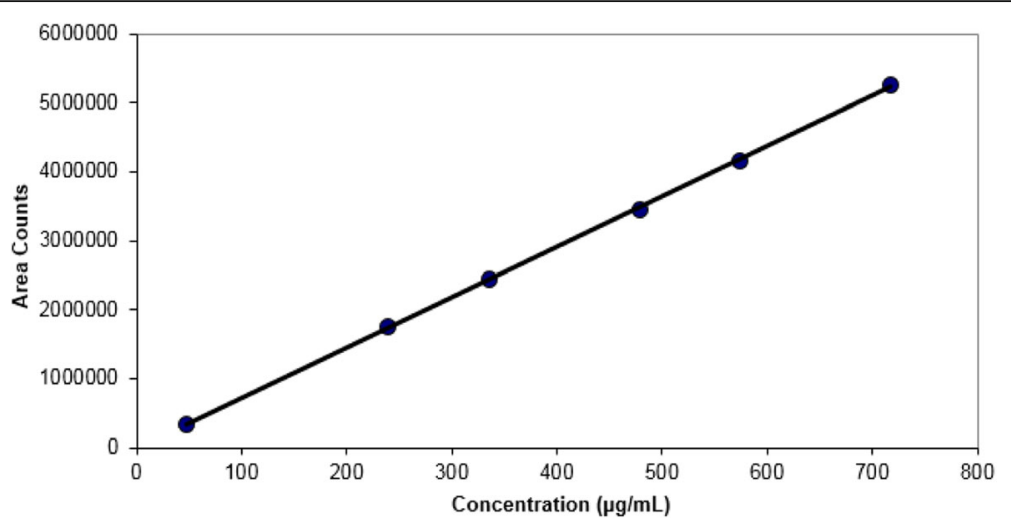

Fig. 3 Linearity of gliclazide. a Preparation of blank, $\mathbf{b}$ Preparation of standard

$\%$ degradation $=$ $\frac{\text { Peak area of untreated stock solution - Peak area of treated stock solution }}{\text { Peak area of untreated stock solution }} \times 1$ 00

\section{Results}

\section{Specificity (selectivity)}

Well, separation of degradation products and gliclazide in terms of purity angle and purity threshold was revealed from forced degradation studies. In acid, alkali, and peroxide, significant degradation was observed as shown in Fig. 2.

\section{Linearity}

Using a plot between concentrations vs area, the linearity of the detector was established. Gliclazide standard was diluted in a series in the range of concentration from 48 to $725 \mu \mathrm{g} / \mathrm{mL}$ from gliclazide stock solution $(1000 \mu \mathrm{g} / \mathrm{mL})$ and analyzed according to a test method. Plotting of graph was done by keeping concentration in $\mu \mathrm{g} / \mathrm{mL}$ on $X$-axis and response (area) on $Y$-axis and the slope, intercept, and the correlation coefficient was determined (Fig. 3).

The linearity plot results of gliclazide are given in Table 2.

\section{Precision}

\section{System precision}

For determining related substances, system precision was performed by analyzing the system suitability

Table 2 Linearity plot results of gliclazide

\begin{tabular}{ll}
\hline Parameter & Observation \\
\hline Slope & 7228.8621 \\
Intercept & -13415.1160 \\
Correlation & 0.999899704 \\
Residual sum of square & 3118705907 \\
\hline
\end{tabular}

mixture six times and gliclazide peak area RSD was found to be $0.84 \%$ (Table 3 ).

\section{Method precision}

For precision, evaluation of test method was done by doing assay for six separate test preparations of $60 \mathrm{mg}$ strength as per test method. The percentage RSD result of assay from six individual test preparations was found to be within the specified limit (Table 4).

\section{Accuracy (recovery)}

A recovery study was done for gliclazide intact tablets in the range of 50 to $150 \%$ of the initial assay concentration. Solutions of the samples were made in triplicate at the individual level and according to the test, method analyses were done. Percentage recovery, percentage mean recovery, and percentage RSD were calculated for all the level results obtained were within limit (Table 5).

\section{Solution stability}

Benchtop stability of standard preparation and test preparation

Benchtop stability of standard preparation and test preparations was established by conducting a study for $24 \mathrm{~h}$. For studying the standard solution's benchtop stability, similarity factor was calculated. The difference in assay percentage between initial and after $24 \mathrm{~h}$ of test preparations is observed to be in the limit. The similarity factor results of the standard were found in between 0.98 and 1.02 which concluded that the standard preparation and test preparations are stable for $24 \mathrm{~h}$ in the benchtop.

\section{Benchtop stability study of mobile phase}

A 3-day study was conducted for establishing the benchtop stability of the mobile phase. According to test method, system suitability parameters were checked by taking 5 replicate injections of standard solution using the same mobile phase on various days. For 3 days, the results of system suitability were obtained within the 
Table 3 Result of system precision

\begin{tabular}{ll}
\hline Injection number & Peak area \\
\hline 1 & 3417135 \\
2 & 3437162 \\
3 & 3381424 \\
4 & 3370534 \\
5 & 3370306 \\
6 & 3373095 \\
Average & 3391609.333 \\
SD & 28534.63979 \\
$\%$ RSD & 0.84 \\
\hline
\end{tabular}

limits. Haziness was not detected and the solution was found clear during the stability testing period. It was concluded from the tests that the mobile phase was stable for 3 consecutive days on the benchtop.

\section{Robustness}

\section{Flow rate variation}

For determining the effect of flow rate variation, a study was conducted using five replicate injections of the standard solution. For higher and lower flow rates of 0.6 $\mathrm{mL} / \mathrm{min}$ and $0.8 \mathrm{~mL} / \mathrm{min}$, system suitability parameters were in the acceptable limits from which, it is concluded that the permissible variation in flow rate is in range of 0.6 to $0.8 \mathrm{~mL} / \mathrm{min}$ which proves that the method is robust for variation of flow rate in the given range.

\section{Column oven temperature variation}

For determining the effect of the column oven temperature variation, a study was performed. Using five replicate injections of standard solution, evaluation of system suitability parameters was done at $40{ }^{\circ} \mathrm{C}$ and 50 ${ }^{\circ} \mathrm{C}$ column oven temperatures. At both column oven temperatures, results of system suitability were found to be within the limits from which, it can be concluded that the permissible variation in column oven temperature is in range of 40 to $50{ }^{\circ} \mathrm{C}$ which proves that the method is robust for variation in the column temperature in the given range.

\section{Variation in $\mathrm{pH}$ of mobile phase}

For determining the effect of the mobile phase $\mathrm{pH}$ variation, a study was conducted. Evaluation of system suitability parameters using five replicate injections of the standard solution was done at $\mathrm{pH} 3.8$ and 4.2. The system suitability results were found to be within the limits at both $\mathrm{pH}$ which concluded that the permissible variation in $\mathrm{pH}$ is in range of 3.8 to 4.2 which proves that the method is robust for variation of mobile phase $\mathrm{pH}$ in the given range.

\section{Variation in composition of mobile phase}

For determining the effect of variation in organic composition of mobile phase, a study using five replicate injections of the standard solution was conducted. Preparation of the mobile phase was done by changing the volume of the individual organic component in the mobile phase by absolute $\pm 10 \%$. Evaluation of system suitability parameters was done using the above mobile phases, and results were found within the acceptable limits for mobile phases which shows that the method is robust for variation in the mobile phase organic composition in the given range.

\section{Application of the method}

Analysis of samples of commercial formulations suggested that the developed method is selective and specific for the determination of gliclazide and its potential impurities in pharmaceutical dosage forms.

\section{Discussion}

Method development

UPLC chromatographic condition development and its optimization

The primary objective for developing a stabilityindicating UPLC method was the detection and determination of the impurities in gliclazide pharmaceutical

Table 4 Result of method precision

\begin{tabular}{lllll}
\hline Sample number & Injection $\mathbf{1}$ area & Injection 2 area & Mean area & \% Assay \\
\hline 1 & 3340504 & 3337686 & 3339095 & 97.5 \\
2 & 3348688 & 3352607 & 3350647 & 97.9 \\
3 & 3357953 & 3349257 & 3353605 & 97.9 \\
4 & 3344406 & 3348032 & 3346219 & 97.7 \\
5 & 3342399 & 3350527 & 3346463 & 97.7 \\
6 & 3351862 & 3347991 & 3349265 & 97.8 \\
Mean & & & 97.8 \\
SD & & & 0.151657509 \\
\%RSD & & & 0.2 \\
\hline
\end{tabular}


Table 5 Result of accuracy study

\begin{tabular}{lllll}
\hline \% Level & Sample no. & \% Recovery & Mean \% recovery & \% RSD \\
\hline 50 & 1 & 97.8 & & \\
& 2 & 98.2 & 98.0 & 0.29 \\
& 3 & 98.0 & & \\
100 & 1 & 98.8 & & 0.36 \\
& 2 & 98.3 & 98.3 & \\
150 & 3 & 97.9 & & 0.07 \\
& 1 & 97.6 & & \\
\hline
\end{tabular}

dosage forms and to separate all three potential impurities (Imp-A, Imp-C, and Imp-F) along with its degradation products generated while performing stress studies $[14,15]$.

\section{Selection of UPLC column}

Based on the structure of the drug and functional groups present in them considering their hydrophilicity and lipophilicity, the selection of column is done. Gliclazide is a non-polar drug. So, reverse phase chromatography has been chosen [16]. Generally used columns are C8, cyano, $\mathrm{C} 18$, and phenyl columns. Trials were taken in different $\mathrm{pH}$ ranges with different columns such as Kinetex C18, Acquity BEH C18 column, and Acquity CSH C18 column. Finally, Acquity CSH C18 $(50 \mathrm{~mm} \times 2.1 \mathrm{~mm}, 1.7$ microns) column was selected based on the highest carbon load, better plate count, and better retention time

a Preparation of Blank:-

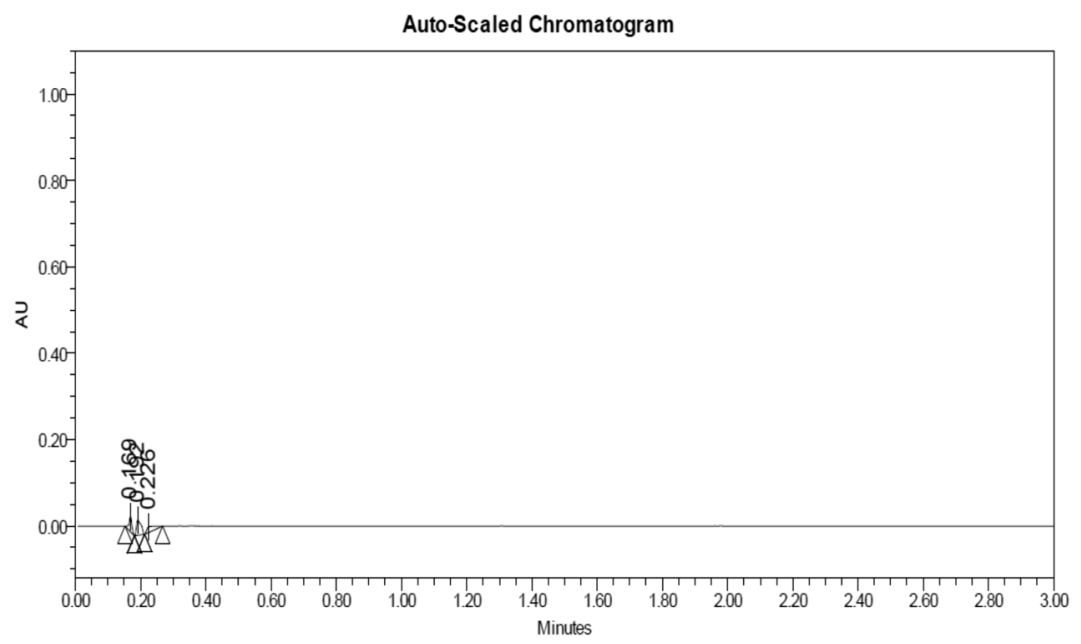

b Preparation of Standard:-

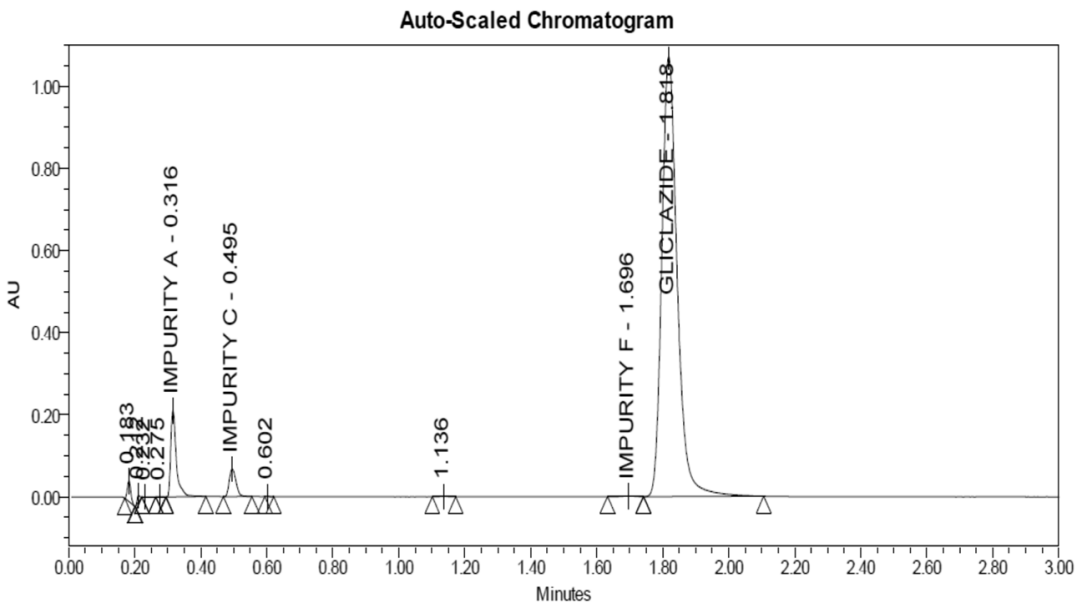

Fig. 4 UPLC chromatograms of blank preparation and standard preparation. a Unspiked standard sample. b Spiked standard sample 
a Unspiked test sample:-

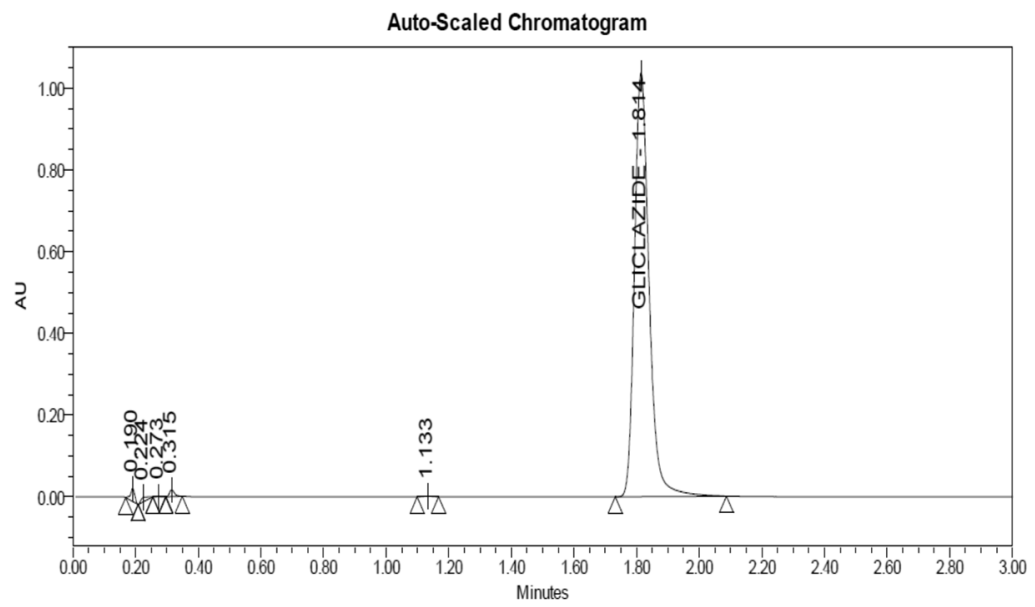

b Spiked test sample:-

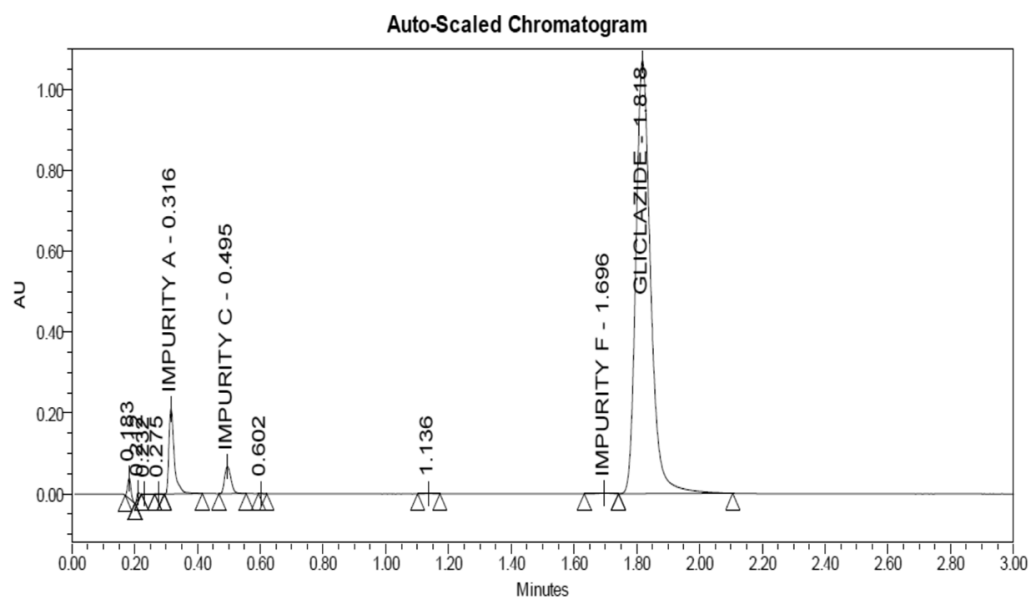

Fig. 5 UPLC chromatograms of test sample preparations. a Unspiked test sample. b Spiked test sample

with no interference with impurity peaks. As mobile phase $\mathrm{pH}$ was nearly 4.0, Acquity CSH C18 (50 mm $\times$ $2.1 \mathrm{~mm}, 1.7$ microns) column is used which can be used in $\mathrm{pH}$ range $1-11[17,18]$.

\section{Buffer selection}

Ammonium acetate which is an organic buffer was selected as buffer having $\mathrm{pKa}-4.8$ and $\mathrm{pH}$ range 3.8-5.8.
Ammonium acetate $\mathrm{pH}$ was adjusted using formic acid which makes the mobile phase compatible with LC-MS. It also improves the resolution. As the stationary phase gets rapidly degraded by inorganic buffers and due to their corrosive nature, they are not considered for this method development. Organic buffers were chosen which were less corrosive than inorganic buffers but gave an equal buffering performance to that of inorganic

Table 6 System suitability study results

\begin{tabular}{lll}
\hline System suitability parameters & Observed value & Acceptance criteria \\
\hline USP plate count & 8047 & ${ }^{b} 2000$ \\
Tailing factor $^{2}$ & 1.3 & ${ }^{c} 2.0$ \\
\% Relative standard deviation $^{a}$ & 0.84 & ${ }^{c} 2.0$ \\
\hline
\end{tabular}

${ }^{\mathrm{a}}$ Six replicate injections

${ }^{b}$ Not less then

${ }^{\mathrm{c}}$ Not more than 
buffers. On the other hand, precipitation problems with organic buffer are less compared to inorganic buffers [19].

\section{Selection of mobile phase}

Mobile phase selection is mainly affected by the dissociation constant, drug solubility. Mixtures of solvents are used sometimes for better resolution of the components. Gliclazide is having pKa 5.8. Ninety-nine percent of gliclazide exists in the unionized form at $\mathrm{pH}$ lower than 2 units away from $\mathrm{pKa}$ and fully ionized at $\mathrm{pH}$ above 2 units of pKa. At higher $\mathrm{pH}$ 7.0, the main peak of gliclazide was merging with the peak of impurity F. As pH decreased to 4 , there was a marked separation between the main peak of gliclazide and the peak of impurity F. Various $\mathrm{pH}$ combinations using potassium dihydrogen phosphate and ammonium acetate with acetonitrile were tried but impurity separation was found maximum at $\mathrm{pH}$ 4.0. Finally, the mobile phase selected was $65 \%$ ammonium acetate buffer of $\mathrm{pH} 4.0+35 \%$ mixture of $10 \%$ ammonium acetate buffer of $\mathrm{pH} 4.0$ and $90 \%$ acetonitrile $[20,21]$.

\section{Optimization of chromatographic conditions}

A wavelength of $227 \mathrm{~nm}$ was chosen for the analysis which is the UV maxima of gliclazide. Based on peak height, peak area, and peak shape, the volume of injection can be chosen. Using various injection volumes, trials were taken. Gliclazide has high absorbance at lower microliters so $2 \mu \mathrm{l}$ was used. Finally, at $2 \mu \mathrm{l}$ injection volume, a good peak shape with the required peak area was obtained. Retention and degradation of the drug depend on column oven temperature. An elevation in column temperature in certain limit may cause a decrease in the viscosity of the mobile phase which in turn will reduce the retention time of analyte. The separation was good at $45{ }^{\circ} \mathrm{C}$ temperature. To get the required resolution with impurities, $45{ }^{\circ} \mathrm{C}$ was selected as the temperature of column. The reason behind selecting the flow rate of 0.5 $\mathrm{mL} / \mathrm{min}$ for the $2.1-\mathrm{mm}$ internal diameter column was that there was a decrease in the resolution between Imp$\mathrm{F}$ and gliclazide to less than 2.0 with an increased flow rate which was not within acceptable limits. Impurity-A, impurity- $\mathrm{C}$, impurity- $\mathrm{F}$, and gliclazide were retained in stationary phase for about $0.316,0.495$, and $1.696 \mathrm{~min}$ respectively (Figs. 4 and 5), and the UPLC method developed was found to be very specific for determining gliclazide and its potential impurities in the pharmaceutical dosage forms [22].

\section{Identification of impurities}

At desired concentrations of $0.15 \%$, impurities A, C, and $\mathrm{F}$ were spiked in gliclazide concerning a test concentration of $480 \mu \mathrm{g} \mathrm{mL}^{-1}$ for confirming the retention times for the chosen method of chromatography. All the impurities were well separated from each other.

\section{System suitability criteria}

Based on obtained results in chromatograms, a system suitability test was conducted. USP plate count obtained from the analyte peak was more than 2000 which determined the column efficiency. Tailing factor was found less than 2.0 and in six replicate injections for system suitability, relative standard deviation (RSD) for impurity areas was found less than $5.0 \%$. During validation of the method criteria for system suitability were found within limits. System suitability results are given in Table 6.

\section{Conclusion}

A simple, sensitive, stability-indicating, and precise UPLC method for estimation of gliclazide has been developed and validated for determining gliclazide in commercial tablet dosage form of $60 \mathrm{mg}$. The compound and its impurities were well separated isocratically on a C18 column (Acquity CSH C18, $1.7 \mu, 50 \times 2.1 \mathrm{~mm}$ ) using a mobile phase consisting of $65 \% \mathrm{pH} 4.05 \mathrm{mM}$ ammonium acetate buffer and 35\% mixture of $10 \%$ buffer and $90 \%$ acetonitrile with a flow rate of $0.7 \mathrm{~mL} / \mathrm{min}$ with UV detection at $227 \mathrm{~nm}$ wavelength. The procedure was validated for all compendial and non-compendial parameters in accordance with ICH guidelines. Stress studies concluded that gliclazide undergoes degradation during acid, base, peroxide, and water-based stress studies but is stable to humidity and thermal stress conditions. The performed study demonstrated that the reverse phased liquid chromatography is selective and sensitive for detecting gliclazide and its potential impurities. After taking trials using different $\mathrm{C} 18$ columns having different carbon loads and different properties, maximum resolution was found with Acquity $\mathrm{CSH}$ C18, $1.7 \mu, 50 \times 2.1 \mathrm{~mm}$ column having high carbon load and less particle size. Validation of the above developed method was done using various validation parameters like system suitability, linearity, precision, specificity, accuracy, solution stability, filter interference, and robustness which were found to be within the acceptance criteria. The developed method is found to be sensitive, precise, accurate, and stability-indicating, resolving all the potential degradation products from the drug.

\section{Abbreviations \\ ICH: International Conference on Harmonization; SD: Standard deviation; LC- MS: Liquid chromatography-mass spectrometry; RSD: Relative standard deviation; UPLC: Ultra performance liquid chromatography; UV: Ultraviolet- visible}

\section{Acknowledgements}

The authors wish to thank NGSM Institute of Pharmaceutical Science, Mangalore, and Mylan Laboratories R\&D Center, Hyderabad, for supporting this work. 


\section{Authors' contributions}

JM carried out the design of analytical method development. KB carried out analytical method development and analytical method validation. KB and JM drafted the manuscript and participated in the design and coordination of the manuscript. JM reviewed the manuscript. All authors read and approved the final manuscript.

\section{Funding}

Not applicable

\section{Availability of data and materials}

All data and materials are available upon request.

\section{Declarations}

Ethics approval and consent to participate

Not applicable

\section{Consent for publication}

Not applicable

\section{Competing interests}

The authors declare that they have no conflict of interests.

\section{Author details}

'Department of Pharmaceutical Chemistry, NETES Institute of Pharmaceutical Science, Mirza, Guwahati 781125, India. ${ }^{2}$ Department of Pharmaceutical Chemistry, NGSM Institute of Pharmaceutical Sciences, Nitte (Deemed to be University), Deralakatte, Mangalore 575018, India.

Received: 25 January 2021 Accepted: 16 April 2021

Published online: 04 May 2021

\section{References}

1. Smith T, Gerich JE (2006) Insulin secretagogues. Clin Diabetes 18:293-304

2. Sunitha R, Venugopal K, Satyanarayana S (2018) Formulation and development studies on enhancement of dissolution rate of BCS class $\|$ antidiabetic drug. Int J Drug Dev Res 10(3):1-6

3. de Mapa BC, Araújo LU, Silva-Barcellos NM, Caldeira TG, Souza J (2020) Gliclazide: biopharmaceutics characteristics to discuss the biowaiver of immediate and extended release tablets. Appl Sci 10(20):1-15

4. Chen LL, Liao YF, Zeng TS, Yu F, Li HQ, Feng Y (2010) Effects of metformin plus gliclazide compared with metformin alone on circulating endothelial progenitor cell in type 2 diabetic patients. Endocrine 38(2):266-275. https:// doi.org/10.1007/s12020-010-9383-8

5. Chan SP, Colagiuri S (2015) Systematic review and meta-analysis of the efficacy and hypoglycemic safety of gliclazide versus other insulinotropic agents. Diabetes Res Clin Pract 110(1):75-81. https://doi.org/10.1016/j.dia bres.2015.07.002

6. O'Brien RC, Luo M, Balazs N, Mercuri J (2000) In vitro and in vivo antioxidant properties of gliclazide. J Diabetes Complications 14(4):201-206. https://doi. org/10.1016/S1056-8727(00)00084-2

7. Kirkman MS, Mahmud H, Korytkowski MT (2018) Intensive blood glucose control and vascular outcomes in patients with type 2 diabetes mellitus. Endocrinol Metab Clin North Am 47(1):81-96. https://doi.org/10.1016/j.ecl.2 017.10 .002

8. Pratima NA, Gadikar R (2018) Liquid chromatography-mass spectrometry and its applications: a brief review.Arc Org Inorg Chem Sci 1(1):26-34.

9. Alrubaye AF, Hameed IH, Kadhim MJ (2017) A review: uses of gas chromatography-mass spectrometry (GC-MS) technique for analysis of bioactive natural compounds of some plants. Int J Toxicol Pharmcol Res 99(1):81-85

10. Niessen WMA, Tjaden UR, Van GJ (1993) Capillary electrophoresis-mass spectrometry. J Chromatogr A. 636(1):3-19. https://doi.org/10.1016/0021 9673(93)80051-9

11. International Federation of Pharmaceutical Manufactures \& Associations (IFPMA) (1996) Validation of analytical procedure. In: International conference on harmonization $(\mathrm{ICH})$, methodology Q2(R1), Geneva: ICH Secretariat
12. The United States Pharmacopeia. Validation of compendial methods,32nd edition.2009; USP 32 Section <1225> http://www.pharmacopeia.cn/v29240/ usp29nf24s0_c1225.html.

13. Hamrapurkar P, Patil P, Desai M, Phale M, Pawar S (2011) Stress degradation studies and development of a validated stability-indicating-assay-method for determination of diacerein in presence of degradation products. Pharm Methods. 2(1):30-35. https://doi.org/10.4103/2229-4708.81088

14. Akula A, Prajwala N, Sandhya M, Maheswara Rao U (2013) Development and validation of RP-HPLC method for simultaneous estimation of metformin hydrochloride and gliclazide in bulk and combined doasage form. Int J Pharm Pharm Sci. 5(4):511-517

15. Venkateswara RB, Vidyadhara S, Ganesh Kumar TNV, Mareswara RDV (2014) RP-HPLC method development and validation for the simultaneous estimation of metformin and sitagliptin in bulk and pharmaceutical formulations. Der Pharm Lett. 6(5):301-307

16. Mounika G, Sahoo S (2020) Estimate gliclazide simultaneously in tablet dosage form by RP-HPLC. Int J Adv Res Med Pharm Sci 5(2):1-8.

17. Patil VP, Tathe RD, Devdhe SJ, Angadi SS, Kale SH (2011) Ultra performance liquid chromatography: a review. Int J Pharm. 2(6):39-44

18. Samatha Y, Srividya A, Ajitha A, Rao VU (2015) Ultra performance liquid chromatography (UPLC). World J Pharm Pharm Sci. 4(6):356-367

19. Konermann L (2017) Addressing a common misconception: ammonium acetate as neutral $\mathrm{pH}$ "buffer" for native electrospray mass spectrometry. J Am Soc Mass Spectrum. 28(9):1827-1835. https://doi.org/10.1007/s13361-01 7-1739-3

20. Dong MW, Boyes BE (2018) Modern trends and best practices in mobilephase selection in reversed-phase chromatography. LC-GC Eur. 31(10):572583

21. Agrahari V, Bajpai M, Nanda S (2013) Essential concepts of mobile phase selection for reversed phase HPLC. Res J Pharm Technol. 6(5):459-464

22. Gedawy A, Salami H, Dass CR (2019) Development and validation of a new analytical HPLC method for simultaneous determination of the antidiabetic drugs, metformin and gliclazide. J Food Drug Anal. 27(1):315-322. https:// doi.org/10.1016/j.jfda.2018.06.007

\section{Publisher's Note}

Springer Nature remains neutral with regard to jurisdictional claims in published maps and institutional affiliations.

\section{Submit your manuscript to a SpringerOpen ${ }^{\bullet}$ journal and benefit from:}

- Convenient online submission

- Rigorous peer review

- Open access: articles freely available online

High visibility within the field

- Retaining the copyright to your article

Submit your next manuscript at $>$ springeropen.com 